\title{
Acetylcholinesterase of the sand fly, Phlebotomus papatasi (Scopoli): cDNA sequence, baculovirus expression, and biochemical properties
}

\author{
Kevin B Temeyer ${ }^{1 *}$, Danett K Brake ${ }^{1,2}$, Alexander P Tuckow ${ }^{1}$, Andrew Y Li and Adalberto A Pérez de León ${ }^{1}$
}

\begin{abstract}
Background: Millions of people and domestic animals around the world are affected by leishmaniasis, a disease caused by various species of flagellated protozoans in the genus Leishmania that are transmitted by several sand fly species. Insecticides are widely used for sand fly population control to try to reduce or interrupt Leishmania transmission. Zoonotic cutaneous leishmaniasis caused by L. major is vectored mainly by Phlebotomus papatasi (Scopoli) in Asia and Africa. Organophosphates comprise a class of insecticides used for sand fly control, which act through the inhibition of acetylcholinesterase (AChE) in the central nervous system. Point mutations producing an altered, insensitive AChE are a major mechanism of organophosphate resistance in insects and preliminary evidence for organophosphate-insensitive AChE has been reported in sand flies. This report describes the identification of complementary DNA for an AChE in P. papatasi and the biochemical characterization of recombinant P. papatasi AChE.
\end{abstract}

Methods: A P. papatasi Israeli strain laboratory colony was utilized to prepare total RNA utilized as template for RT-PCR amplification and sequencing of CDNA encoding acetylcholinesterase 1 using gene specific primers and 3'5'-RACE. The cDNA was cloned into pBlueBac4.5/N5-His TOPO, and expressed by baculovirus in Sf21 insect cells in serum-free medium. Recombinant P. papatasi acetylcholinesterase was biochemically characterized using a modified Ellman's assay in microplates.

Results: A 2309 nucleotide sequence of PpAChE1 cDNA [GenBank: JQ922267] of P. papatasi from a laboratory colony susceptible to insecticides is reported with $73-83 \%$ nucleotide identity to acetylcholinesterase mRNA sequences of Culex tritaeniorhynchus and Lutzomyia longipalpis, respectively. The P. papatasi CDNA ORF encoded a 710-amino acid protein [GenBank: AFP20868] exhibiting 85\% amino acid identity with acetylcholinesterases of CX. pipiens, Aedes aegypti, and $92 \%$ amino acid identity for L. longipalpis. Recombinant P. papatasi AChE1 was expressed in the baculovirus system and characterized as an insect acetylcholinesterase with substrate preference for acetylthiocholine and inhibition at high substrate concentration. Enzyme activity was strongly inhibited by eserine, BW284C51, malaoxon, and paraoxon, and was insensitive to the butyrylcholinesterase inhibitors ethopropazine and iso-OMPA.

Conclusions: Results presented here enable the screening and identification of PpAChE mutations resulting in the genotype for insensitive PpAChE. Use of the recombinant P. papatasi AChE1 will facilitate rapid in vitro screening to identify novel PpAChE inhibitors, and comparative studies on biochemical kinetics of inhibition.

Keywords: Sand fly, Acetylcholinesterase, P. papatasi, cDNA, AChE

GenBank: JQ922267, AFP20868

\footnotetext{
* Correspondence: Kevin.Temeyer@ars.usda.gov

'Knipling-Bushland U.S. Livestock Insects Research Laboratory, Agricultural Research Service, U. S. Department of Agriculture, 2700 Fredericksburg Road, Kerrville, TX 78028-9184, USA

Full list of author information is available at the end of the article
} 


\section{Background}

Over 350 million people are at risk of suffering from leishmaniasis and over 2 million new cases are reported each year, which makes it one of the most neglected diseases globally $[1,2]$. The sand-fly Phlebotomus papatasi (Scopoli) is the vector of the flagellate protozoan Leishmania major that causes zoonotic cutaneous leishmaniasis [3-5] in Asia and Africa [1,6,7]. Various species of burrowing rodents are reservoir hosts of $L$. major and sand flies are closely associated with the rodent burrows making vector control by direct insecticidal application difficult to achieve [6,8-10]. Prevention of Leishmania spp. transmission to humans is largely reliant on vector control to avoid insect bites by use of screens, insecticide impregnated bed nets or curtains, establishment of barrier zones by insecticide applications, or environmental modification $[2,9,11,12]$. Use of synthetic sand fly pheromone as an attractant was reported to improve effectiveness of pesticide application for control of the new world sand fly Lutzomyia longipalpis in chicken sheds [13]. Attempts to control Phlebotomus papatasi by various types of insecticide application has had questionable effectiveness, particularly in the harsh environments reported during combat operations by the U.S. military in Iraq $[14,15]$, although there was no evidence of significant insecticide resistance.

Insecticide resistance is an increasing problem in control of insect vectors of disease and there have been reports of possible resistance in sand fly populations to various insecticides $[2,11,16]$. Pesticide effectiveness for knockdown of Phlebotomine sand flies in Morocco was found to be variable for different fly populations, reflective of past history of high pesticide use in some areas for malaria control, although all of the sand flies tested as susceptible to the pesticides by bioassay, suggesting possible genetic changes that might lead to development of resistance [17]. Preliminary evidence for an altered acetylcholinesterase (E.C. 3.1.1.7, AChE) was reported in the sand fly Phlebotomus argentipes from Sri Lanka [18], and from Phlebotomus papatasi in Khartoum State, Sudan [19], each possibly the result of widespread use of insecticides in the Anti-Malarial Campaign. Coutinho-Abreu et al. [20] reported that the AChE gene of Lutzomyia longipalpis (Lutz \& Neiva) appears to be structurally similar to other insect species in which point mutations result in an altered enzyme insensitive to organophosphate or carbamate inhibitors. Organophosphate pesticides function as quasi-irreversible inhibitors of $\mathrm{AChE}$, resulting in failure of the central nervous system and death of the insect. Point mutations within the sequence encoding $\mathrm{AChE}$ resulting in production of an altered, insensitive enzyme have been reported to be a major mechanism of organophosphate resistance in insects [21-26]. Determination of the nucleotide sequence encoding $\mathrm{AChE}$ of $P$. papatasi should enable rapid identification of mutations potentially associated with resistance, and the development of rapid molecular tests to screen $P$. papatasi populations for the presence of specific mutations. Confirmation of $\mathrm{AChE}$ mutations resulting in production of an insensitive $\mathrm{AChE}$ is expected to facilitate the development of rapid molecular tests for pesticide resistance in sand flies. This report describes the identification of complementary DNA for AChE1 in P. papatasi and the biochemical characterization of recombinant P. papatasi AChE1 produced using a baculovirus expression system.

\section{Methods}

\section{Sand flies}

Sand flies used in this study were from a $P$. papatasi colony maintained at the USDA-ARS, Knipling-Bushland U.S. Livestock Insects Research Laboratory in Kerrville, Texas. The colony was established using pupae from an Israeli strain of $P$. papatasi maintained for 30 years and never exposed to pesticides at the Division of Entomology, Walter Reed Army Institute of Research (Silver Spring, Maryland). The colony is therefore considered to be generally susceptible to insecticides and baseline data on pesticide susceptibility by bioassay of colony sand flies is being collected for publication (A. Li, personal communication). Larvae were fed with a sand fly larval diet, a mixture of fermented rabbit feces and rabbit food [27]. Both larvae and adult flies were maintained at $26 \pm 2^{\circ} \mathrm{C}$ and a relative humidity of $85 \pm 2 \%$. Males were fed with $30 \%$ sucrose water and females were fed with defibrinated cattle blood using an in vitro membrane feeding system. Larvae and newly emerged unfed adult male flies were collected and quick-frozen by immersion in liquid nitrogen, and stored at $-70^{\circ} \mathrm{C}$ until use.

\section{RNA preparation}

Total RNA was prepared from frozen whole larvae or unfed adults by grinding in a glass tissue homogenizer containing Tri-Reagent (Sigma Chemical, St. Louis, MO) or by use of a MagMAX ${ }^{\mathrm{TM}}-96$ RNA Isolation Kit (Life Technologies, Carlsbad, CA) according to the manufacturers' instructions.

\section{Oligonucleotide synthesis}

Synthetic oligodeoxynucleotides were purchased from Sigma-Genosys (The Woodlands, TX).

\section{cDNA synthesis}

Complementary DNA (cDNA) was synthesized by reverse transcription from template RNA using the SuperScript ${ }^{\mathrm{TM}}$ Choice System for cDNA Synthesis (Life Technologies) according to the manufacturer's instructions. Oligodeoxynucleotide primers were oligo $\left(\mathrm{dT}_{18} \mathrm{~V}\right)$ or gene-specific primers based on known sequence. 


\section{Polymerase chain reaction (PCR)}

We utilized automatic hot-start PCR using AmpliTaq Gold ${ }^{\circledR}$ DNA polymerase (Applied Biosystems, Foster City, CA) or Advantage ${ }^{\circledR} 2$ HF DNA Polymerase (BD Biosciences Clontech, Mountain View, CA) according to the manufacturers' instructions.

\section{Agarose gel electrophoresis}

DNA preparations generated from PCR, RT-PCR, or bacterial plasmids were analyzed by agarose gel electrophoresis in tris-borate-EDTA buffer by standard techniques [28]. DNA bands were visualized by staining with GelStar ${ }^{\circledR}$ Nucleic Acid Gel Stain (Cambrex, Rockland, MD) and photographed on a Kodak GelLogic 440 Imaging system (Eastman Kodak Co., Rochester, NY) with uv illumination.

\section{Rapid Amplification of cDNA Ends (RACE)}

5'- and 3'-RACE was performed using the SMARTer ${ }^{\mathrm{TM}}$ RACE cDNA Amplification Kit (BD Biosciences Clontech, Palo Alto, CA).

\section{DNA cloning}

Double-stranded cDNA was inserted into bacterial plasmid DNA using the TOPO TA Cloning ${ }^{\circledR}$ Kit for Sequencing (Invitrogen, Carlsbad, CA), transformed into One Shot ${ }^{\circledR}$ TOP10 chemically competent Escherichia coli (Invitrogen) for amplification, screened for appropriate inserts by PCR, and sequenced by normal sequencing procedures (see below).

\section{DNA sequencing}

For sequencing, PCR amplification reactions were scaled up to $50 \mu \mathrm{l}$ and purified using ExoSAP-IT ${ }^{\circledR}$ (Affymetrix, Santa Clara, CA). The sequencing reaction using BigDye ${ }^{\circledR}$ terminator (Applied Biosystems) and precipitation of the products with ethanol were performed according to the manufacturer's instructions. Sequencing products were analyzed on a PRISM 3130xl Genetic Analyzer (Applied Biosystems).

\section{Analysis of amino acid or nucleotide sequences}

Sequence analysis to design oligonucleotide primers used for PCR or sequencing utilized OLIGO ${ }^{\circledR}$ Primer Analysis Software, Version 5.0 (1996, National Biosciences Inc, Plymouth, MN). Sequence chromatograms and sequence assembly utilized ChromasPro ver. 1.32 (Technelysium Pty Ltd., available at http://technelysium.com.au/?page_id=27). Clustal W (http://www.ebi.ac.uk/Tools/msa/clustalw2/) was used to perform multiple sequence alignments [29]. BLAST search of GenBank (http://blast.ncbi.nlm.nih.gov/Blast.cgi), [30] and on-line protein sequence analyses were done using ExPASy Proteomics tools.

\section{PpAChE expression construct}

Double stranded cDNA containing the complete PpAChE1 coding sequence [GenBank: JQ922267] was obtained by PCR amplification of cDNA using PpAce18F-273U23 and PpAce18F-2561 L20 (Table 1) using an annealing temperature of $62.5^{\circ} \mathrm{C}$ and extension time of $3 \mathrm{~min}$. at $72^{\circ} \mathrm{C}$. The cDNA was cloned into pBlueBac4.5/V5-His TOPO $^{\circledR}$ (Applied Biosystems/Life Technologies) and sequenced to verify proper construction.

\section{Baculovirus expression of recombinant PpAChE}

PpAChE1 clones were constructed, sequenced, and expressed as baculovirus expression clones in Sf21 insect cells in sf900 III serum-free medium (Life Technologies/ Gibco) as previously described [31,32]. Serum-free cell culture baculovirus lysates were collected and centrifuged to remove cell debris and supernatants were used for biochemical characterization of recombinant PpAChE1.

\section{Biochemical characterization of rPpAChE1}

AChE activity of baculovirus culture supernatant was measured by a modified Ellman's method as described previously [33] except that the reaction was monitored every minute for $30 \mathrm{~min}$ to establish initial velocity. For inhibition studies, rPpAChE was preincubated with an appropriate concentration of the inhibitor at $23^{\circ} \mathrm{C}$ for $10 \mathrm{~min}$ in $100 \mu \mathrm{l}$ in the microtiter plate without substrate or DTNB [(5'.5'-dithiobis-(2-nitrobenzoic acid)] and $\mathrm{AChE}$ activity was monitored for $10 \mathrm{~min}$ after initiation of the reaction by addition of $100 \mu$ l substrate and DTNB. Cholinesterase inhibitors included the AChE-specific inhibitors eserine and BW284c51, butyrylcholinesterasespecific inhibitors ethopropazine and iso-OMPA, and oxidized organophosphates, paraoxon and malaoxon. All chemicals were of reagent grade obtained from Sigma Chemical Co. Data were analyzed and plotted using GraphPad Prism ver. 5.0 (GraphPad Prism, Inc., La Jolla, CA).

\section{Results}

Beginning with a presumptive acetylcholinesterase partial sequence (111 nucleotides) of Phlebotomus perniciosus [GenBank: AJ865843], we constructed oligodeoxynucleotide primers for 5'-, and 3'-RACE to obtain the complete PpAChE cDNA sequence [GenBank: JQ922267] (Additional file 1). Both strands were sequenced for the entire presumptive coding sequence of the cDNA at least three times. Oligodeoxynucleotide primers used for sequencing or 3'-15'-RACE are listed in Table 1 . The sequence obtained for the presumptive PpAChE1 cDNA of $P$. papatasi was comprised of 2309 nucleotides organized as a 71-nucleotide 5'-untranslated region, an open reading frame (ORF) of 2130 nucleotides, and a 105nucleotide 3'-untranslated region. BLAST homology search 
Table 1 Oligodeoxynucleotide primers for AChE of $P$. papatasi

\begin{tabular}{lcl}
\hline Oligonucleotide name & Position $^{\mathbf{a}^{\mathbf{a}}}$ & Nucleotide Sequence $^{\mathbf{b}}$ \\
\hline PpAce18F-273U23 & $1-23(\mathrm{U})$ & CAATAACGTGGTATCTCGCATAA \\
PpAChE458U17 & $186-202(\mathrm{U})$ & TTGGCGGAGGGTCGTCA \\
PpAChE552U22 & $280-302(\mathrm{U})$ & TCTTAGGCGAATCAACATTAGA \\
PpAChE550L23 & $300-278(\mathrm{~L})$ & CTAATGTGATTCGCCTAAGACT \\
PpAChE5R-693 L20 & $497-378(\mathrm{~L})$ & CGCTCCAGTGTGCCCAATTC \\
PpAChE20-828U23 & $827-849(\mathrm{U})$ & CTTCGGTGGTGGATTCTACTCAG \\
PpAChEp13-435 L21 & $975-955(\mathrm{~L})$ & CAGGGGCATCAGGAGTACCAA \\
PpAChEp13-719U18 & $1221-1239(\mathrm{U})$ & CTAGCCGAAGCCGTGGAG \\
PpAChE7Jan-590 L22 & $1226-1205(\mathrm{~L})$ & GGCTAGGCGAAGGGTTCTATTG \\
PpAChE7J-887U23 & $1502-1524(\mathrm{U})$ & AGAGGAGGGCATAACTGTAACAC \\
PpAChE7J-947 L22 & $1582-1562(\mathrm{~L})$ & CGCACGGCACCATTGACATAG \\
PpAChE7J-1100U22 & $1715-1736(\mathrm{U})$ & TGAGGAGGGCAACAATGTCTAC \\
PpAce2L27 & $1749-1723(\mathrm{~L})$ & TGTAGAGATACATGTAGACATTGTTGC \\
PpAce22L18 & $1760-1743(\mathrm{~L})$ & GGTGCGATGGGTGTAGAG \\
PpAce18F-2561 L20 & $2309-2289(\mathrm{~L})$ & GAGTAAATCGCGTTACTTCA \\
\hline
\end{tabular}

${ }^{\mathrm{a}}$ Position (based on PpAChE sequence numbering, Figure 1).

'Sequence is 5's3', upper (U) or lower (L) strand.

[30] of GenBank (11,299,630 sequences) found significant nucleotide identity (73-83\%) to the AChE mRNA sequences of a mosquito, Culex tritaeniorhynchus [GenBank: AB122152] and for the new world sand fly L. longipalpis (partial codes, 1188 nucleotides, [GenBank: DQ898276]) respectively, as well as to other arthropod AChEs.

The $P$. papatasi AChE cDNA ORF encodes a 710-amino acid protein [GenBank: AFP20868]; $79451 \mathrm{MW}, 5.77 \mathrm{pI}$, http://web.expasy.org/compute_pi/) exhibiting 85\% amino acid identity with AChEs of mosquitoes, Culex pipiens [GenBank: Q86GC8], Aedes aegypti [GenBank: XP_001 656977], and $92 \%$ amino acid identity with the new world sand fly, L. longipalpis AChE (partial codes, 396 amino acids, [GenBank: ABI74669]. Comparison of the amino acid sequence of $\mathrm{PpAChE1}$ with the $\mathrm{AChE}$ protein of $L$. longipalpis (partial codes) and the AChEs of Cx. pipiens and Ae. aegypti by Clustal W multiple sequence alignment is shown in Figure 1. As seen in Figure 1, there was very high amino acid identity throughout the partial sequence of $L$. longipalpis $\mathrm{AChE}$ as well as substantial identity with the two mosquito AChEs. Presumptive disulfide bonds, members of the catalytic triad, and residues lining the catalytic gorge $[34,35]$ are indicated in the Clustal W multiple sequence alignment with AChEs of Torpedo californica [GenBank: 1EA5_A] and Drosophila melanogaster [GenBank: 1QO9_A] (Additional file 2).

Recombinant PpAChE1 was expressed in the baculovirus system and used for biochemical characterization. Biochemical properties (substrate $K_{\mathrm{m}}$ and relative sensitivities to inhibitors) obtained for $\mathrm{rPpAChE1}$ are presented in Table 2 . The enzyme was strongly inhibited by eserine, paraoxon, malaoxon, and the acetylcholinesterase inhibitor Bw284c51 and exhibited much lower sensitivity to the butyrylcholinesterase inhibitors iso-OMPA and ethopropazine. In addition, $\mathrm{rPpAChE} 1$ hydrolyzed $0.1 \mathrm{mM}$ acetylthiocholine (AcSCh) 17-fold faster than $0.1 \mathrm{mM}$ butyrylthiocholine (BuSCh), demonstrating substrate preference for AcSCh over BuSCh and was inhibited at substrate concentrations above $5 \mathrm{mM}$.

\section{Discussion}

Biochemical properties of $\mathrm{rPpAChE1}$ presented in this report are consistent with classification as an insect acetylcholinesterase as defined by Toutant [36]. There is substrate preference for acetylthiocholine over butyrylthiocholine, significant inhibition by the AChE-specific inhibitors eserine and BW284c51 with relative insensitivity to inhibitors (ethopropazine and iso-OMPA) classified as specific for butyrylcholinesterase. The enzyme is strongly inhibited by paraoxon and malaoxon (oxidized forms of parathion and malathion) and exhibits a $K_{\mathrm{m}}$ for acetylthiocholine $(37.9 \mu \mathrm{M})$ similar to values reported for recombinant acetylcholinesterases of Ae. aegypti $(13.79 \mu \mathrm{M})$ [37], Stomoxys calcitrans $(63.9 \mu \mathrm{M})$ [33], Haematobia irritans $(31.3 \mu \mathrm{M})$ [38], or Musca domestica $(150 \mu \mathrm{M})$ [39].

P. papatasi is a significant public health problem in the Middle East, Asia and Africa where it transmits L. major that causes zoonotic cutaneous leishmaniasis in humans [40]. Additionally, zoonotic cutaneous leishmaniasis can seriously affect the operational readiness of United States military personnel deployed in Iraq and Afghanistan [41]. Attempts by the U.S. military to control sand flies through the use of chemical pesticides were not highly successful, 

P. papatasi
L. longipalpis
C. pipiens
A. aegypti
P. papatasi
L. Iongipalpis
C. pipiens
A. aegypti
MEIRGIVVTTMRPFTGIHSGVDQMFVICLLSLLGVMCQLAEGRHHDLSNTQSFKSGPKHI 60 MEIRGLITRLLGPCHLRH - - - - LILCSLGLYSILVQSVHCRHHDIGSSVAHQLGSKYS 54 MEIRGLITRLLGPCHIRH - - - - - LILCSLGIYSILVQSVHCRHHDIGSSTAHQLGSKYS 54
ASVEAAAVSVLGESTLEVSSESDDT - - IFTPYLGHGDAVRVVDAELGTLEREGVSAGSDG 118 QSSSLSSSSQSSSSLAEEATLNKDSDAFFTPYIGHGDSVRIVDAELGTLEREHIHS- - 110 QSSSLSSSSQSSSSLVEDPVLNKDSDAFFTPYIGHGDSVRIVDAELGTLEREHVHS - - - 110
P. papatasi
L. longipalpis
C. pipiens
A. aegypti

P. papatasi

L. longipalpis

C. pipiens

A. aegypti
P. papatasi
L. longipalpis
C. pipiens
A. aegypti

P. papatasi

L. longipalpis

C. pipiens

A. aegypti
P. papatasi
L. longipalpis
C. pipiens
A. aegypti

P. papatasi

L. Iongipalpis

C. pipiens

A. aegypti
P. papatasi
L. longipalpis
C. pipiens
A. aegypti

P. papatasi

L. Iongipalpis

C. pipiens

A. aegypti

P. papatasi

L. longipalpis

C. pipiens

A. aegypti
P. papatasi
L. longipalpis
C. pipiens
A. aegypti

TSQPRRRNISRRESNPDAEENDPLIVTTDKGKVRGVTLTSPTGKKVDAWMGIPYAQPPVG 178

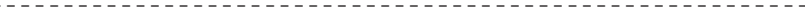

- TTTRRRGLTRRESSSDATDSDPLVITTDKGKIRGTTLEAPSGKKVDAWMGIPYAQPPLG 169 -TTTRRRGLTRRESSSDGTDNDPLLITTDKGKVRGLTLEAPSGKKVDAWLGI PYAQPPLG 169

ALRFRHPRPAERWSGILNATTPPNTCVQIVDTLFGDFPGATMWNPNTNLTEDCLYINVAV 238

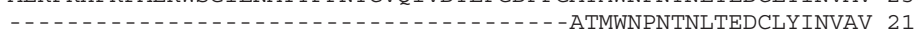
PLRFRHPRPAERWTGVLNATKPPNSCVQIVDTVFGDFPGATMWNPNTPLSEDCLYINVVV 229 PLRFRHPRPVEKWTGVLNATTPPNSCVQIVDTVFGDFPGATMWNPNTPLSEDCLYINVVV 229

$$
\star * * * * * * * *: * * * * * * * * \text {. }
$$

PHPRPKNSPVMLWIFGGGFYSGTSTLDVYDHRTLVAEENI ILVSMQYRVASLGFLYLGTP 298 PHPRPKNSPVMLWIFGGGFYSGTSTLDVYDHRTLVAEENI ILVSMOYRVASLGFLYLGTP 81 PRPRPKNAAVMLWIFGGGFYSGTATLDVYDHRTLASEENVIVVSLQYRVASLGFLFLGTP 289 PHPRPKNSAVMLWIFGGGFYSGTATLDVYDHRTLASEENVIVVSLQYRVASLGFLFLGTP 289 $*: * * * * *: . * * * * * * * * * * * * *: * * * * * * * * * * .: * * *: *: * *: * * * * * * * * * *: * * * *$

$$
\neq
$$

DAPGNAGLFDQHLALRWVRNNIHRFGGDPTRVTLFGESAGAVSVSMHLLSSLSHDLFQRA 358 DAPGNAGLFDQNLALRWVRDNIHRFGGDPTRVTLFGESAGAVSVSMHLLSALSHDLFQRA 141 EAPGNAGLFDQNLALRWVRDNIHRFGGDPSRVTLFGESAGAVSVSLHLLSALSRDLFQRA 349 EAPGNAGLFDQNLALRWVRDNIHKFGGDPSRVTLFGESAGAVSVSLHLLSALSRDLFQRA 349

$: * * * * * * * * * *: * * * * * * *: * * *: * * * * *: * * * * * * * * * * * * * * *: * * * *: * *: * * * * * *$

ILOSGSPTAPWALITRDEAINRTLRLAEAVECPHNRDELSEVLECLRSRDAKOLVNNEWN 418 ILQSGSPTAPWALMTREEAINRALRLADAVECPHDRDNLPEVVECLRGRDAKQLVNNEWH 201 ILQSGSPTAPWALVSREEATLRALRLAEAVNCPHDATKLSDAVECLRTKDPNELVDNEWG 409 ILQSGSPTAPWALVSREEATLRALRLAEAVNCPHDATKLTDTVECLRTKDPNVLVDNEWG 409

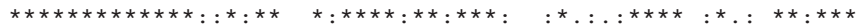

$\neq$

NLGICEFPFVPVVDGSFLDESPQRAMATGRFEKTDILTGSNTEEGYYFIIYYLTELLRKE 478 NLGICEFPFVPVVDGAFLDETPQRSLATGRFKKTDILTGSNTEEGYYFI IYYLTELLRKE 261 TLGICEFPFVPVVDGAFLDETPQRSLASGRFKKTDILTGSNTEEGYYFIIYYLTELLRKE 469 TLGICEFPFVPVVDGAFLDETPQRSLASGRFKKTDILTGSNTEEGYYFI IYYLTELLRKE 469 $. * * * * * * * * * * * * * *: * * * *: * * *:: *: * * *: * * * * * * * * * * * * * * * * * * * * * * * * * * * *$

3

EGITVTREEFLKAVRELNPYVNGAVRQAIVFEYTDWTDPDNAHSNRDALDKMVGDYHFTC 538
EGITVTREEFLKAVEELDPYVNGAARQAIVFEYTDWTDPDNAHSNRDALDKMVGDYHFTC 321 EGITVTREEFLKAVEELDPYVNGAARQAIVFEYTDWTDPDNAHSNRDALDKMVGDYHFTC 321 EGVTVSREEFLQAVRELNPYVNGAARQAIVFEYTDWTEPENPNSNRDALDKMVGDYHFTC 529

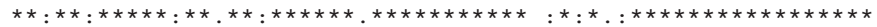

$$
\text { : }
$$

NVNEFAHRYAEEGNNVYMYLYTHRTKANPWPRWTGVMHGDEINYVFGEPLNPSLTYTDEE 598 NVNEFAHRYAEEGNNVFMYLYTHRSKGNPWPRWTGVMHGDE INYVFGEPLNSALSYTEEE 381 NVNEFAQRYAEEGNNVFMYLYTHRSKGNPWPRWTGVMHGDEINYVFGEPLNSALGYQDDE 589 NVNEFAQRYAEEGNNVYMYLYTHRSKGNPWPRWTGVMHGDEINYVFGEPLNSDLGYMEDE 589

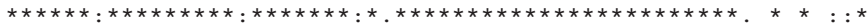

KEFSRRIMRYWVNFAKTGNPNPGFVS-NLPDWPKHTAHGRQYMELGLNTTYLGRGPRLRQ 657

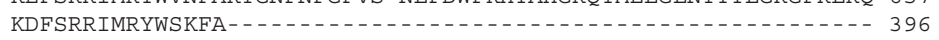
KDFSRKIMRYWSNFAKTGNPNPSTPSVDLPEWPKHTAHGRHYLELGLNTTFVGRGPRLRQ 649 KDFSRKIMRYWSNFAKTGNPNPSPPNSDFPEWPKHTAHGRHYLELGLNTTYVGRGPRLRQ 649 $*: * * *: * * * *: * *$ 3 CAFWKKYLPQLMAATIENSSTKNCTNVGNQFVRNPNFSIPTTLLVILGILSVN - - - - 710

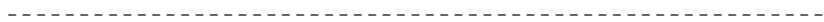
CAFWKKYLPQLVAAT----SNLQVTPAPSVPCESSSTSYRSTLLLIVTLLLVTRFKI 702 CAFWKKYLPQLVAAT----SNLQATPAPSEPCGSSATPYRPLLFLIVSLVLVTCFKI 702

Figure 1 Clustal W 2.1 multiple sequence alignment of AChE protein sequences for Phlebotomus papatasi [GenBank: JQ922267], Lutzomyia longipalpis [GenBank: ABI74669], Culex pipiens AChE [GenBank: Q86GC8], and Aedes aegypti [GenBank: XP_001656977]. The consensus line below the aligned sequences indicates positions of conserved amino acid identity $\left(^{*}\right)$ or similarity (: or .). Positions of the 3 disulfide bond linkages are indicated by numbers above participating cysteine pairs. The members of the catalytic triad (S, E, $H$ ) which make up the catalytic site are indicated by $(\neq)$ above the participating amino acid. 
Table 2 Biochemical properties of rPpAChE

\begin{tabular}{ll}
\hline Property $^{\mathbf{a}}$ & PpAChE $^{\mathbf{b}}$ \\
\hline$K_{\mathrm{m}}$ AcSCh $(\mu \mathrm{M})$ & $37.9 \pm 1.6$ \\
$I C_{50}$ Paraoxon $\left(10^{-7} \mathrm{M}\right)$ & $2.3(1.9-2.7)$ \\
$I C_{50}$ Malaoxon $\left(10^{-8} \mathrm{M}\right)$ & $2.7(1.7-4.5)$ \\
$I C_{50}$ Eserine $\left(10^{-10} \mathrm{M}\right)$ & $7.2(5.0-10.5)$ \\
$I C_{50}$ BW284c51 $\left(10^{-8} \mathrm{M}\right)$ & $7.1(5.9-8.4)$ \\
$I C_{50}$ Ethopropazine $\left(10^{-6} \mathrm{M}\right)$ & $4.4(4.0-4.9)$ \\
$I C_{50}$ Iso-OMPA & $\mathrm{NC}^{\mathrm{C}}$ \\
\hline
\end{tabular}

${ }^{\mathrm{a}} \mathrm{AcSCh}=$ acetylthiocholine; $\mathrm{IC}_{50}=$ concentration of inhibitor producing $50 \%$ inhibition of enzyme activity during 10 min preincubation.

${ }^{b}$ Data are presented as mean \pm SE or ( $95 \%$ confidence interval).

${ }^{c} \mathrm{NC}=$ not calculated (no inhibition detected at $10^{-3} \mathrm{M}$ ).

possibly due to extreme environmental conditions $[14,15]$, and pesticide bioassays did not reveal evidence of insecticide resistance. Chemical pesticides have been used in several ways for insect control, including area-wide applications for malaria control in the same areas inhabited by $P$. papatasi. Recent reports of pesticide resistance in sand flies, possibly resulting from insensitive AChE $[18,19]$, highlight the urgent need to characterize the mechanisms responsible for insecticide resistance and the relevance of efforts to develop rapid tests to identify resistant pest populations.

Point mutations in pest AChEs have been shown to generate altered enzymes with decreased inhibition by organophosphate [16,21,42-45]. The present report demonstrating very high amino acid sequence identity of the P. papatasi AChE to those of Cx. pipiens and Ae. aegypti strongly suggests that this PpAChE1 is the target site for organophosphate and will facilitate identification of PpAChE1 mutations that produce insensitivity to organophosphate or carbamate pesticides.

In mosquito vectors, very high resistance to OPs and carbamates results from a single amino acid substitution of Serine for Glycine (codon GGC, PpAChE1 pos 837, Gly $\rightarrow$ AGC, Ser) [46-50]. Ae aegypti is reported to have the GGA codon at this position (as does our PpAChE1), and when converted to AGC, the $A$. aegypti enzyme has the identical high level resistance as Anopheles [49]. It has been suggested that GGA at this position is extremely unlikely to evolve to AGC, and that in nature, only Gly or Ser are found at this position, which indicates that no other amino acids are allowed in $\mathrm{AChE} 1$ at that position [49]. Our results suggest significant OP-insensitivity in AChE of $P$. papatasi would be unlikely to involve PpAChE1, unless nucleotide pos 839 exists in a polymorphic state (i.e., GGA/C) in nature. Alternatively, it is hypothesized that, if present, other AChEs in P. papatasi could provide the mechanism to develop target insensitivity as documented in Ae. aegypti where a high level of AChE insensitivity was due to substitutions at positions F455W (Tc pos Phe331) and Ile697 of AChE2 [51,52].

\section{Conclusions}

Use of the recombinant $P$. papatasi AChE1 will facilitate rapid in vitro screening to identify novel PpAChE inhibitors, and comparative studies on biochemical kinetics of inhibition. Information on the identification and characterization of PpAChE1 presented here will facilitate the development of a rapid molecular assay for the GGC codon (pos. 839) in P. papatasi populations, and other molecular tools to screen for mutations giving rise to an organophosphate-insensitive PpAChE1. Molecular data on PpAChE1 could also be used in modeling studies to predict in vivo insecticidal activity for novel inhibitors as described by Naik et al. [53]. Availability of the recombinant PpAChE1 will enable the creation of mechanism-based screens to discover more effective inhibitors that may be developed to innovate safer vector control technologies. Novel synthetic carbamates have already been identified by screening using the recombinant $\mathrm{PpAChE}$ that present essentially equivalent inhibition of the target AChE with substantially improved target specificity resulting in significantly enhanced safety [Swale DR, Tong F, Temeyer KB, Li AY, Totrov MM, Carlier PR, unpublished].

\section{Endnotes}

${ }^{1}$ This article reports the results of research only. Mention of a proprietary product does not constitute an endorsement by the USDA for its use.

${ }^{2}$ In conducting research described in this report, investigators adhered to the "Guide for the Care and Use of Laboratory Animals," as promulgated by the Committee on Care and Use of Laboratory Animals of the Institute of Laboratory Animal Resources, National Research Council. A protocol describing routing procedures for animal care and use is on file with the Animal Care Committee at the research location.

${ }^{3} \mathrm{USDA}$ is an equal opportunity provider and employer.

${ }^{4}$ Copyright statement: Copyright protection is not available for any work of the United States Government.

${ }^{5}$ Disclaimer: "The views expressed in this article are those of the authors and do not necessarily reflect the official policy or position of the Department of the Navy, Department of Defense, nor the U.S Government."

\section{Additional files}

Additional file 1: Figure S1. Nucleotide and amino acid sequences are listed for Phlebotomus papatasi AChE for rPpAChE-16 expressed in the baculovirus system.

Additional file 2: Figure S2. Clustal W 2.1 multiple sequence alignment of AChE protein sequences for Torpedo californica [GenBank: 1EA5_A], Phlebotomus papatasi (rPpAChE-16), and Drosophila melanogaster AChE [GenBank: 1Q09_A]. The consensus line below the aligned sequences indicates positions of conserved amino acid identity $\left(^{*}\right)$ or similarity (: or.). Positions of the 3 disulfide bond linkages are indicated by numbers above 
participating cysteine pairs. The members of the catalytic triad $(\mathrm{S}, \mathrm{E}, \mathrm{H})$ which make up the catalytic site are indicated by $(\neq)$ above the participating amino acid. Positions lining the catalytic gorge are indicated by $(\boldsymbol{\nabla})$ above the participating amino acid [32,33].

\section{Abbreviations}

(AChE): Acetylcholinesterase; (DTNB): Dithiobisnitrobenzoic acid; (AcSCh): Acetylthiocholine; (BuSCh): Butyrylthiocholine; (rPpAChE1): Recombinant $P$. papatasi AChE1.

\section{Competing interests}

The authors declare that they have no competing interests.

\section{Authors' contributions}

KBT, AYL, and AAPdL conceived experiments to clone the PpAChE and biochemically characterize its recombinant form. KBT designed experiments and supervised laboratory tests to identify, clone, sequence, and express rPpAChE in the baculovirus system. DKB and APT conducted biochemical assays and data analysis of rPpAChE1. AYL and AAPdL obtained DWFP funding, maintained the sand fly colony, and provided sand flies for experimental use. All authors contributed to writing and revision of the manuscript and approved the final version.

\section{Acknowledgements}

The authors thank Kristie Schlechte, DeEsta Hyatt and Darci Burchers for excellent technical assistance. The authors also thank Dr. Fan Tong and Dr. Donald Thomas for critical review of the manuscript. This work was funded by U.S. Department of Agriculture [USDA] appropriated funds (USDA-ARS CRIS number 6205-32000-033000D, Molecular biology and physiology of biting flies affecting livestock) and USDA-ARS CRADA number 60-0208-9-601 (Project number 6201-32000-033017R, Deployed Warfighter Protection Research Program [DWFP] of the U.S. Department of Defense through the Armed Forces Pest Management Board [AFPMB]).

\section{Author details}

${ }^{1}$ Knipling-Bushland U.S. Livestock Insects Research Laboratory, Agricultural Research Service, U. S. Department of Agriculture, 2700 Fredericksburg Road, Kerrville, TX 78028-9184, USA. ${ }^{2}$ Present address: Medical Service Corps, U.S. Navy, Wound Infections Dept., Naval Medical Research Center, 503 Robert Grant Ave, Silver Spring, MD 20910-7500, USA.

Received: 27 September 2012 Accepted: 10 January 2013

Published: 4 February 2013

\section{References}

1. World Health Organization: Cutaneous leishmaniasis: Why are you neglecting me?. 2007 [http://whqlibdoc.who.int/hq/2007/ WHO CDS NTD_IDM 2007.3 eng.pdf]

2. World Health Organization: Control of the leishmaniases. WHO Technical Report Series; no. 949: Report of a meeting of the WHO Expert Committee on the Control of Leishmaniases, Geneva, 22-26 March 2010; 2010 [http://whqlibdoc.who.int/trs/WHO_TRS_949_eng.pdf]

3. Jaffe $\mathrm{CL}$, Baneth $\mathrm{G}$, Abdeen ZA, Schlein $Y$, Warburg A: Leishmaniasis in Israel and the Palestinian Authority. Trends Parasitol 2004, 20:328-332.

4. Kravchenko V, Wasserberg G, Warburg A: Bionomics of phlebotomine sandflies in the Galilee focus of cutaneous leishmaniasis in northern Israel. Med Vet Entomol 2004, 18:418-428.

5. Killick-Kendrick R, Leaney AJ, Peters W, Rioux J-A, Bray RS: Zoonotic cutaneous leishmaniasis in Saudi Arabia: the incrimination of Phlebotomus papatasi as the vector in the Al-Hassa oasis. Trans R SoC Trop Med Hyg 1985, 79:252-255.

6. Mascari TM, Mitchell MA, Rowton ED, Foil LD: Evaluation of juvenile hormone analogues as rodent feed-through insecticides for control of immature phlebotomine sandflies. Med Vet Entomol 2011, 25:227-231.

7. Mirzaei A, Rouhani S, Taherkhani H, Farahmand M, Kazemi B, Hedayati M, Baghaei A, Davari B, Parvizi P: Isolation and detection of Leishmania species among naturally infected Rhombomis opimus, a reservoir host of zoonotic cutaneous leishmaniasis in Turkeman Sahara, North East of Iran. Exp Parasitol 2011, 129:375-380.
8. Rassi Y, Oshaghi MA, Azani SM, Abaie MR, Rafizaheh S, Mohebai M Mohtarami F, Zeinali M: Molecular detection of Leishmania infection due to Leishmania major and Leishmania turanica in the vectors and reservoir host in Iran. Vector Borne Zoonotic Dis 2011, 11:145-150.

9. Schlein Y, Müller GC: Experimental control of Phlebotomus papatasi by spraying attractive toxic sugar bait (ATSB) on vegetation. Trans $R$ Soc Trop Med Hyg 2010, 104:766-771.

10. Wasserberg G, Poche R, Miller D, Chenault M, Zollner G, Rowton ED: Imidacloprid as a potential agent for the systemic control of sand flies. J Vector Ecol 2011, 36(Suppl 1):S148-S156.

11. Alexander B, Maroli M: Control of phlebotomine sandflies. Med Vet Entomol 2003, 17:1-18.

12. Kassi M, Kasi PM, Marri SM, Tareen I, Khawar T: Vector control in cutaneous leishmaniasis of the old world: a review of literature. Dermatol Online J 2008, 14:1.

13. Bray DP, Alves GB, Dorval ME, Brazil RP, Hamilton JGC: Synthetic sex pheromone attracts the leishmaniasis vector Lutzomyia longipalpis to experimental chicken sheds treated with insecticide. Parasit Vectors 2010, 3:16

14. Colacicco-Mayhugh MG, Grieco JP, Putnam JL, Burkett DA, Coleman RE: Impact of phlebotomine sand flies on United States Military Operations at Tallil Air Base, Iraq: 5. Impact of weather on sand fly activity. J Med Entomol 2011, 48:538-545.

15. Coleman RE, Burkett DA, Sherwood V, Caci J, Dennett JA, Jennings BT, Cushing R, Cushing RJ, Ploch J, Hopkins G, Putnam JL: Impact of phlebotomine sand flies on United State military operations at Tallil Air Base, Iraq: 6. Evaluation of insecticides for the control of sand flies. J Med Entomol 2011, 48:584-599.

16. Hemingway J, Ranson H: Insecticide resistance in insect vectors of human disease. Annu Rev Entomol 2000, 45:371-391.

17. Faraj C, Ouahabi S, Adlaoui EB, Elkohli ME, Lakraa L, Rhazi ME, Ameur B: Insecticide susceptibility status of Phlebotomus (Paraphlebotomus) sergenti and Phlebotomus (Phlebotomus) papatasi in endemic foci of cutaneous leishmaniasis in Morocco. Parasit Vectors 2012, 5:51.

18. Surendran SN, Karunaratne SHPP, Adams Z, Hemingway J, Hawkes NJ: Molecular and biochemical characterization of a sand fly population from Sri Lanka: evidence for insecticide resistance due to altered esterases and insensitive acetylcholinesterase. Bull Entomol Res 2005, 95:371-380.

19. Hassan MM, Widaa SO, Osman OM, Numiary MSM, Ibrahim MA, Abushama HM: Insecticide resistance in the sand fly, Phlebotomus papatasi from Khartoum State, Sudan. Parasit Vectors 2012, 5:46.

20. Coutinho-Abreu IV, Balbino VQ, Valenzuela JG, Sonoda IV, Ramalho-Ortigão JM: Structural characterization of acetylcholinesterase 1 from the sand fly Lutzomyia longipalpis (Diptera: Psychodidae). J Med Entomol 2007, 44:639-650.

21. Fournier D, Mutero A: Modification of acetylcholinesterase as a mechanism of resistance to insecticides. Comp Biochem Physiol C Toxicol Pharmacol 1994, 108:19-31.

22. Mutero A, Pralavorio M, Bride JM, Fournier D: Resistance-associated point mutations in insecticide insensitive acetylcholinesterase. Proc Natl Acad Sci USA 1994, 91:5922-5926.

23. Zhu KY, Clark JM: Comparisons of kinetic properties of acetylcholinesterase from azinphosmethyl-susceptible and resistant strains of Colorado potato beetle. Pest Biochem Physiol 1995, 51:57-67.

24. Zhu KY, Lee SH, Clark JM: A point mutation of acetylcholinesterase associated with azinphosmethyl resistance and reduced fitness in Colorado potato beetle. Pest Biochem Physiol 1996, 55:100-108.

25. Villatte F, Ziliani P, Marcel V, Nenozzi P, Fournier D: A high number of mutations may provide insecticide-resistance in insect acetylcholinesterase. Pest Biochem Physiol 2000, 67:95-102.

26. Menozzi P, Shi MA, Lougarre A, Tang AH, Fournier D: Mutations of acetylcholinesterase which confer insecticide resistance in Drosophila melanogaster populations. BMC Evol Biol 2004, 4:4

27. Young DG, Perkins PV, Endris RG: A larval diet for rearing Phlebotomine sand flies (Diptera, Psychodidae). J Med Entomol 1981, 18:446.

28. Ausubel FM, Brent R, Kingston RE, Moore DD, Seidman JG, Smith JA Struhl K: Current Protocols in Molecular Biology. Hoboken: John Wiley \& Sons: Ausubel FM, Brent R, Kingston RE, Moore DD, Seidman JG, Smith JA, Struhl K; 2003

29. Thompson JD, Higgins DG, Gibson TJ: CLUSTAL W: Improving the sensitivity of progressive multiple sequence alignment through 
sequence weighting, position-specific sequence gap penalties and weight matrix choice. Nucleic Acids Res 1994, 22:4673-4680.

30. Altschul SF, Madden TL, Schäffer AA, Zhang J, Zhang Z, Miller W, Lipman DJ: Gapped BLAST and PSI-BLAST: a new generation of protein database search programs. Nucleic Acids Res 1997, 25:3389-3402.

31. Temeyer KB, Pruett JH Jr, Untalan PM, Chen AC: Baculovirus expression of BmAChE3, a cDNA encoding an acetylcholinesterase of Boophilus microplus (Acari: Ixodidae). J Med Entomol 2006, 43:707-712.

32. Temeyer KB, Pruett JH Jr, Olafson PU, Chen AC: R86Q, a mutation in BmAChE3 yielding a Rhipicephalus microplus organophosphateinsensitive acetylcholinesterase. J Med Entomol 2007, 44:1013-1018.

33. Temeyer KB, Chen AC: Acetylcholinesterase of Stomoxys calcitrans (L.) (Diptera: Muscidae): cDNA sequence, baculovirus expression, and biochemical properties. Vet Parasitol 2012, 184:92-95.

34. Harel M, Kryger C, Tosenberry TL, Mallender WD, Lewis T, Fletcher RJ, Guss JM, Silman I, Sussman JL: Three-dimensional structures of Drosophila melanogaster acetylcholinesterase and of its complexes with two potent inhibitors. Protein Sci 2000, 9:1063-1072.

35. Sussman JL, Harel M, Frolow F, Oefner C, Goldman A, Toker L, Silman I: Atomic structure of acetylcholinesterase from Torpedo californica: a prototypic acetylcholine-binding protein. Science 1991, 253:872-879.

36. Toutant J-P: Insect acetylcholinesterase: catalytic properties, tissue distribution and molecular forms. Prog Neurobiol 1989, 32:423-446.

37. Anthony N, Rocheleau T, Mocelin G, Lee H-J, french-Constant R: Cloning, sequencing and functional expression of an acetylcholinesterase gene from the yellow fever mosquito Aedes aegypti. FEBS Lett 1995, 368:461-465.

38. Temeyer KB, Brake DK, Schlechte KG: Acetylcholinesterase of Haematobia irritans (Diptera: Muscidae): baculovirus expression, biochemical properties, and organophosphate insensitivity of the G262A mutant. $J$ Med Entomol 2012, 49:589-594.

39. Walsh SB, Dolden TA, Moores GD, Kristensen M, Lewis T, Devonshire AL, Williamson MS: Identification and characterization of mutations in housefly (Musca domestica) acetylcholinesterase involved in insecticide resistance. Biochem J 2001, 359:175-181.

40. Jacobson RL: Leishmaniasis in an era of conflict in the Middle East. Vector Borne Zoonotic Dis 2011, 11:247-258.

41. Lay JC: Leishmaniasis among U.S. armed forces, January 2003-November 2004. Medical surveillance monthly report. U S Army Center Health Promotion Preventive Med 2004, 10:2-5.

42. Fournier D, Mutero A, Pralavorio M, Bride J-M: Drosophila acetylcholinesterase: mechanisms of resistance to organophosphates. Chem Biol Interact 1993, 87:233-238.

43. Feyereisen R: Molecular biology of insecticide resistance. Toxicol Lett 1995, 82/83:83-90.

44. Kozaki T, Tomita T, Taniae K, Yamakawa M, Kono Y: Expression of two acetylcholinesterase genes from organophosphate sensitive- and insensitive-houseflies, Musca domestica L. (Diptera: Muscidae), using a baculovirus insect cell system. Appl Entomol Zool 2002, 37:213-218.

45. Vontas JG, Hejazi MJ, Hawkes NJ, Cosmidis N, Loukas M, Hemingway J: Resistance-associated point mutations of organophosphate insensitive acetylcholinesterase in the olive fruit fly Bactrocera oleae. Insect Mol Biol 2002, 11:329-336.

46. Weill W, Fort P, Berthomieu A, Dubois MP, Pasteur N, Raymond M: A novel acetylcholinesterase gene in mosquitoes codes for the insecticide target and is non-homologous to the ace gene in Drosophila. Proc $R$ Soc Lond B 2002, 269:2007-2016.

47. Weill W, Lutfalla G, Mogensen K, Chandre F, Berthomieu A, Berticat C, Pasteur N, Philips A, Fort P, Raymond M: Corrigendum - Insecticide resistance in mosquito vectors. Nature 2003, 425:366.

48. Weill W, Lutfalla G, Mogensen K, Chandre F, Berthomieu A, Berticat C, Pasteur N, Philips A, Fort P, Raymond M: Insecticide resistance in mosquito vectors. Nature 2003, 423:136-137.

49. Weill W, Berthomieu A, Berticat C, Lutfalla G, Negre V, Pasteur N, Philips A, Leonetti J-P, Fort P, Raymond M: Insecticide resistance: a silent base prediction. Curr Biol 2004, 14:R552.

50. Weill W, Malcolm C, Chandre F, Mogensen K, Berthomieu A, Marquine M, Raymond $\mathrm{M}$ : The unique mutation in ace-1 giving high insecticide resistance is easily detectable in mosquito vectors. Insect Mol Biol 2004, 13:1-7.

51. Nabeshima T, Kozaki T, Tomita T, Kono Y: An amino acid substitution on the second acetylcholinesterase in the pirimicarb-resistant strains of the peach potato aphid, Myzus persicae. Biochem Biophys Res Commun 2003, 307:15-22.
52. Nabeshima T, Mori A, Kozaki T, Iwata Y, Hidoh O, Harada S, Kasai S, Severson DW, Kono Y, Tomita T: An amino acid substitution attributable to insecticide-insensitivity of acetylcholinesterase in a Japanese encephalitis vector mosquito, Culex tritaeniorhynchus. Biochem Biophys Res Commun 2004, 313:794-801.

53. Naik PK, Sindhura TS, Singh H: Quantitative structure-activity relationship (QSAR) for insecticides: development of predictive in vivo insecticide activity models. SAR QSAR Environ Res 2009, 20:551-566.

doi:10.1186/1756-3305-6-31

Cite this article as: Temeyer et al:: Acetylcholinesterase of the sand fly, Phlebotomus papatasi (Scopoli): cDNA sequence, baculovirus expression and biochemical properties. Parasites \& Vectors 2013 6:31.

\section{Submit your next manuscript to BioMed Central and take full advantage of:}

- Convenient online submission

- Thorough peer review

- No space constraints or color figure charges

- Immediate publication on acceptance

- Inclusion in PubMed, CAS, Scopus and Google Scholar

- Research which is freely available for redistribution 